\title{
$t^{4}$ Workshop Report*
}

\section{Current Approaches and Future Role of High Content Imaging in Safety Sciences and Drug Discovery}

Erwin van Vliet ${ }^{1}$, Mardas Daneshian ${ }^{2}$, Mario Beilmann ${ }^{3}$, Anthony Davies $^{4}$, Eugenio Fava ${ }^{5}$, Roland Fleck ${ }^{6}$, Yvon Jule ${ }^{7}$, Manfred Kansy ${ }^{8}$, Stefan Kustermann ${ }^{8}$, Peter Macko ${ }^{9}$, William R. Mundy ${ }^{10}$, Adrian Roth ${ }^{8}$, Imran Shah ${ }^{11}$, Marianne Uteng ${ }^{12}$, Bob van de Water $^{13}$, Thomas Hartung ${ }^{2,14}$ and Marcel Leist ${ }^{2 *}$

${ }^{1}$ Innovitox consultation \& services, Barcelona, Spain; ${ }^{2}$ Center for Alternatives to Animal Testing - Europe (CAAT-Europe), University of Konstanz, Konstanz, Germany; ${ }^{3}$ Department of Non-clinical Drug Safety, Molecular \& Cell Toxicology Group, Boehringer Ingelheim Pharma GmbH \& Co. KG, Biberach, Germany; ${ }^{4}$ Irish National Center for High Content Screening and Analysis (INCHSA), Dublin, Ireland; ${ }^{5}$ German Center for Neurodegenerative Diseases (DZNE), Bonn, Germany; ${ }^{6}$ Biological Imaging and Assay Development, National Institute of Biological Standards and Control, Potters Bar, UK; ${ }^{7}$ Biocellvia, Marseille, France; ${ }^{8}$ Non Clinical Safety, F. Hoffmann-La Roche LTD, Basel, Switzerland; ${ }^{9}$ EURL ECVAM, European Commission - Joint Research Centre, Systems Toxicology Unit, Ispra, Italy; ${ }^{10}$ National Health and Environmental Effects Research Laboratory, US Environmental Protection Agency, Research Triangle Park, NC, USA; ${ }^{11}$ National Center for Computational Toxicology, Office of Research and Development, Research Triangle Park, NC, USA; ${ }^{12}$ Cellular Models \& High Content Biology Laboratory, Novartis International AG, Switzerland; ${ }^{13}$ Leiden Academic Centre for Drug Research, Leiden University, The Netherlands; ${ }^{14}$ Johns Hopkins University, Bloomberg School of Public Health, Center for Alternatives to Animal Testing (CAAT), Baltimore, MD, USA

\section{Summary}

High content imaging combines automated microscopy with image analysis approaches to simultaneously quantify multiple phenotypic and/or functional parameters in biological systems. The technology has become an important tool in the fields of safety sciences and drug discovery, because it can be used for mode-of-action identification, determination of hazard potency and the discovery of toxicity targets and biomarkers. In contrast to conventional biochemical endpoints, high content imaging provides insight into the spatial distribution and dynamics of responses in biological systems. This allows the identification of signaling pathways underlying cell defense, adaptation, toxicity and death. Therefore, high content imaging is considered a promising technology to address the challenges for the

"Toxicity testing in the $21^{\text {st }}$ century" approach. Currently, high content imaging technologies are frequently applied in academia for mechanistic toxicity studies and in pharmaceutical industry for the ranking and selection of lead drug compounds or to identify/confirm mechanisms underlying effects observed in vivo. A recent workshop gathered scientists working on high content imaging

Received May 27, 2014; Epub July 14, 2014; http://dx.doi.org/10.14573/altex.1405271

* a report of $\mathrm{t}^{4}$ - the transatlantic think tank for toxicology, a collaboration of the toxicologically oriented chairs in Baltimore, Konstanz and Utrecht sponsored by the Doerenkamp-Zbinden Foundation; participants do not represent their institutions and do not necessarily endorse all recommendations made.

Disclaimer: This document has been reviewed by the National Health and Environmental Effects Research Laboratory and approved for publication. Approval does not signify that the contents reflect the views of the agency, nor does mention of trade names or commercial products constitute endorsement or recommendation for use. 
in academia, pharmaceutical industry and regulatory bodies with the objective to compile the stateof-the-art of the technology in the different institutions. Together they defined technical and methodological gaps, proposed quality control measures and performance standards, highlighted cell sources and new readouts and discussed future requirements for regulatory implementation. This review summarizes the discussion, proposed solutions and recommendations of the specialists contributing to the workshop.

Keywords: high content imaging, toxicology, drug development, toxicity pathways, mechanistic safety screening

\section{Introduction}

The term high content imaging (HCI) is used to describe automated microscopy combined with image analysis approaches to simultaneously quantify multiple phenotypic and/or functional parameters in biological systems (Giuliano et al., 1997, 2003; Abraham et al., 2004). Typically, multiple morphological (e.g., cell shape, membranes, nuclei, mitochondria) or functional (e.g., signal transduction, gene expression, metabolism) features in either a cell, cell system or lower model organism are labeled using probes (e.g., fluorescent dyes, antibodies, gene reporters), automatically imaged and quantified by imaging analysis algorithms. Assessment of multiple biological parameters in individual cells may lead to more insight into the mechanistic effects of compounds. HCI technologies can also be used for the design of screening assays, with the purpose of testing large numbers of compounds for a limited set of biological parameters to identify hits for further mechanistic studies (Buchser et al., 2004).

$\mathrm{HCI}$ has become an important tool in the field of safety sciences, because it can be used for mode-of-action (MoA) identification, hazard potency determination and the discovery of predictive biomarkers for the mechanistic safety assessment of compounds (Young et al., 2008; Zanella et al., 2010). In contrast to conventional biochemical endpoints that provide quantitative information on a biological readout(s) at a given time-point, $\mathrm{HCI}$ of multiple read-outs in living cells can provide insight into the spatial distribution and dynamics of responses in biological systems over time (Massoud and Gambhir, 2003). The modeling of these dynamic responses across dose and time allows the identification of signaling pathways underlying cellular defense, adaptation, toxicity and death (Mohamed et al., 2011; Herpers and van de Water, 2013; Wink et al., 2014). Therefore, HCI is considered a promising technology to address the challenges laid out in Toxicity Testing in the $21^{\text {st }}$ Century: A Vision and a Strategy (NRC, 2007; Leist et al., 2008; Andersen and Krewski, 2009; Berg et al., 2011; van Vliet et al., 2011).

Research based on HCI technologies has provided insight into toxicity mechanisms for different target organs, such as hepatotoxicity (Kim et al., 2012; Latta et al., 2000; Persson et al., 2013; Trask et al., 2014), neurotoxicity (Leist et al., 2012; Schildknecht et al., 2013; Lotharius et al., 2005; Dragunow, 2008; Stiegler et al., 2011; Harrill et al., 2013; Krug et al., 2013) and cardiotoxicity (Kim et al., 2011; Földes and Mioulane, 2013). Moreover HCI has been used to study and understand the biological mechanisms involved in stem cell differentiation or inflammatory signaling (Barbaric et al., 2010; Henn et al., 2009, 2011; Sherman et al., 2011; Kuegler et al., 2012). In the pharmaceutical industry, tailored HCI assays are used for the ranking and selection of lead drug compounds and to identify or confirm a mechanism for an observed in vivo effect. The high content screening of drug lead compounds in human cell systems has been shown to generate relevant data to support the decision making process (O'Brien et al., 2006; Abraham et al., 2008; Tolosa et al., 2012).

Because of the increasingly important role of $\mathrm{HCI}$ in safety sciences and drug development, a workshop was organized in Mainz, Germany on October 21-23, 2013. Expert scientists from academia, pharmaceutical industry and regulatory organizations were invited to discuss the current and future role of HCI technologies in safety sciences and drug development. On the first day, the scientists presented state-of-the-art HCI studies and discussed the status quo of the technology in their different institutions. On the second day, technical and methodological gaps, the need for quality control and performance standards and the future requirements for implementation into the regulatory framework were discussed. This report aims to summarize the main outcomes and recommendations of the workshop and to facilitate a wider discussion and collaboration within the field to advance the technology and bring it closer to the regulatory context.

\section{High content imaging approaches: status quo}

\subsection{Characteristics and added value of the high content imaging approach}

High content imaging is particularly useful for safety sciences and drug development because it can generate different types of biological, toxicological and pharmacological information that support the interpretation of the safety or efficacy of compounds (Fig. 1). First, it can provide information on biological characteristics of the used biological system to understand the complexity of the in vitro environment in which the compound is studied (Zock, 2009; Scholz et al., 2013). Second, it allows multiple phenotypic and functional read-outs that can be integrated to identify dynamic cell responses to toxicants (Herpers and van de Water, 2013; Wink et al., 2014; Falsig et al., 2004; Lund et al., 2005). Third it can provide information on compound pharmacology, such as its target, efficacy or potency in a screening system (Mulji et al., 2012). Finally, it can be used in combination with siRNA libraries or drug-based cell modifica- 


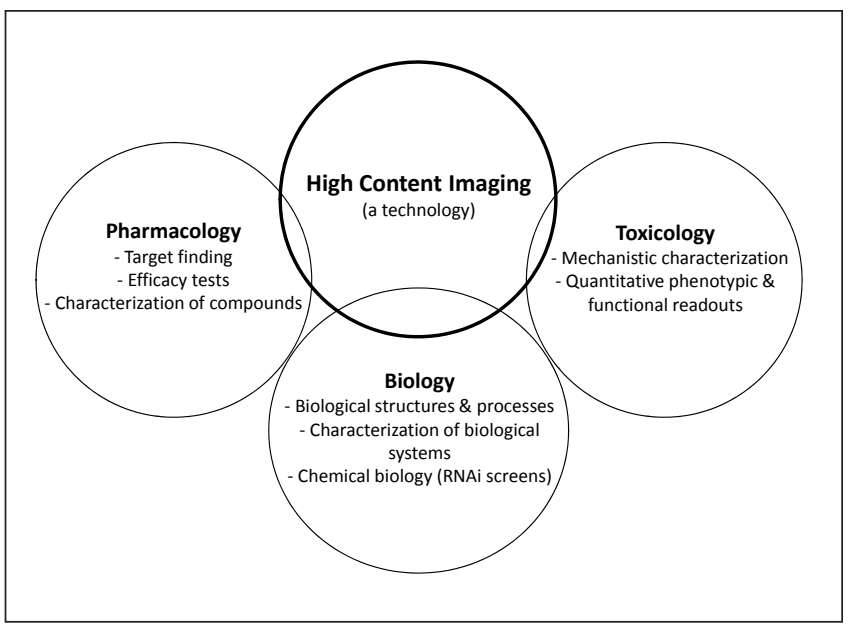

Fig. 1: Use of $\mathrm{HCl}$ technology in different interrelated fields

High content imaging can provide relevant biological, toxicological and pharmacological information to support assay design,

compound safety assessment and drug discovery.

tions to screen targets and MoA of compounds (Krausz, 2007; Verissimo et al., 2012; Benedetti et al., 2013).

Within the field of HCI, there are many different assay designs that make use of the various biological systems, probes and imaging technologies that are currently available. It is difficult to define the exact design characteristics (number of cells analyzed and read-out parameters) an imaging assay should have to be considered as high content, but in general it concerns simultaneous measurement of multiple parameters. A number of general characteristics of HCI were defined during the workshop. These have been summarized in (Box 1).

\section{Box 1: \\ General characteristics of high content imaging \\ - Based on automated imaging technologies \\ - Simultaneous read-outs of multiple quantitative parameters \\ - Allows the acquisition of temporal and spatial information (live cell imaging) \\ - Allows the study of effects at subcellular level (e.g., nucleus, mitochondria, lysosome, or ER) \\ - Allows the differentiation of cell sub-populations in a biological system (e.g., healthy vs. dying cells) \\ - Makes use of probes or biosensors for specific labeling of cellular structures or processes (antibodies, reporters, dyes, auto-fluorescence) \\ - Applies unbiased and automated image analysis algorithms}

The value added by a high content imaging approach compared to the conventional single read-out methods includes:

- The unbiased automated imaging of multiple phenotypic and/ or functional parameters in a living biological system, which provides insight into the dynamics and spatial distribution of biological processes underlying cell homeostasis, defense, adaptation, toxicity and death.
- The data on the multiple phenotypic and/or functional parameters can be integrated and correlated across dose and time to establish multiple concentration-response relationships. Comparison of these relationships allows the differentiation between exposures that, e.g., lead to a loss in cell function, alter the metabolic state or morphology of a cell or organelle, and induce cytotoxicity. The in vitro concentrations at which these different events occur can be used to define in vitro benchmark concentrations for mechanistic safety assessment.

- The differentiation and study of specific cell sub-populations or different organelles in a biological system. The cell subpopulations can be distinguished based on phenotypic or functional characteristics such as cell morphology, maturation, differentiation stage, viability, metabolic state, or cell cycle phase. The cellular phenotype that is the most or the least vulnerable for the toxicity of a compound can provide insight into its MoA. It also creates the opportunity to exclude cell phenotypes that are not relevant for toxicological interpretation (e.g., dying cells) to reduce noise and increase the sensitivity of an assay.

\subsection{Current high content imaging applications in safety sciences}

High content imaging applications have different levels of complexity depending on the safety questions to be answered (Fig. 2 ). The complexity of an assay is mainly determined by the choice of the biological system and imaging technology. A variety of in vitro cell systems (cell lines, co-cultures, 3D cell cultures, and stem cells) and lower model organisms (Caenorhabditis elegans, Danio rerio) are available with different levels of biological complexity. Gene reporters, fluorescent dyes or biosensors for specific cell structures (e.g., membranes, cytosol, nucleus, mitochondria, Golgi) or functional processes (e.g., cell signaling pathways, transport, and energy metabolism) can be visualized for quantification and monitoring over time using image analysis software. The data acquisition can be achieved using either 2D or 3D imaging technologies. 3D imaging generates more accurate results on the shape, size, location and relationship between cellular structures or processes. An even more complex acquisition technology includes the "organ on a chip approach," which uses a 3D microfluidic cell culture chip that can both measure and simulate the activities, mechanics and physiological responses of entire organs or organ systems (Huh et al., 2011; Baker, 2011). Using this approach, multiple biological processes, e.g., in the liver, kidney, lung or heart can be stimulated (pharmacologically or mechanically) during the imaging data acquisition, which allows the investigation of biological mechanisms and responses in organ specific microenvironments (Yum et al., 2014). The obtained imaging datasets are analyzed using imaging analysis algorithms for the automated unbiased extraction of quantitative information. The algorithms can be used to discriminate specific target elements in the images such as cells, organelles, biological structures and processes. These target elements can be traced to define the exact size, shape and volume of biological structures (e.g., vasculature, neurites, microtubules) or tracked over time to show dynamic movements of biological processes (e.g., cell migration, differentiation, 


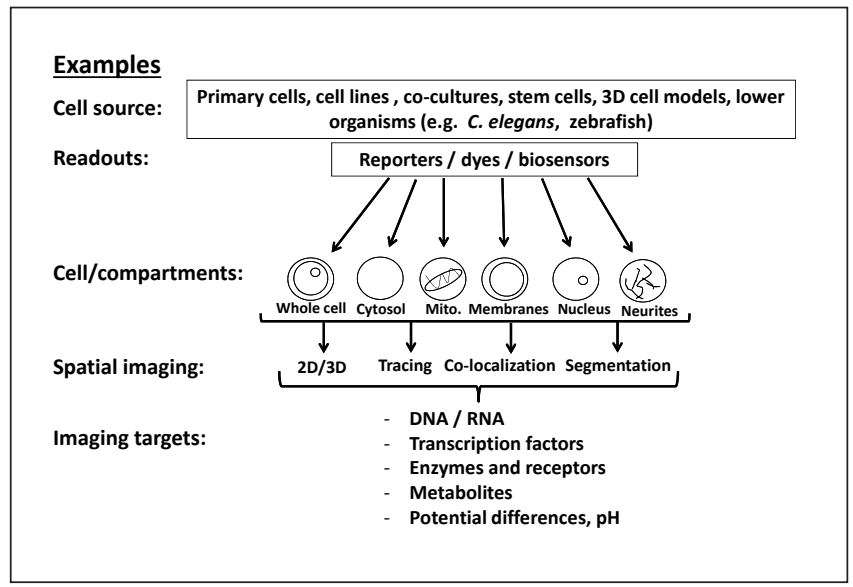

Fig. 2: $\mathrm{HCl}$ has a broad application range

High content imaging approaches have different levels of complexity depending on the biological system, readouts, cell type/compartments, imaging space and target of interest (Mito.: Mitochondria).

neurite outgrowth) (Shariff et al., 2010). Specific alterations in the structure or behavior of target elements can be identified as biomarkers for toxicity (Blaauboer et al., 2012) or MoAs of compounds.

To verify the involvement of particular cell signaling molecules, genes, proteins or metabolites in biological processes or responses, gene silencing technologies such as RNA interference (RNAi) or biochemical inhibitors (antagonist) are often used to inhibit cell-signaling pathways. For toxicity studies, concentration response relationships for the phenotypic and/or functional read-outs are used to identify benchmark concentrations that induce molecular initiating events or induce pathways leading to cell adaptation and toxicity. The in vitro benchmark concentrations can be extrapolated to a dose for comparison with existing in vivo or human data (Yoon et al., 2012; Leist et al., 2012). An important feature of high content screening is that the effects of a compound can also be studied in human cells (e.g., differentiated human stem cells), which is highly relevant information for the safety assessment of drug development.

\subsection{High content imaging case studies}

Major factors that define biological relevance of HCI include the complexity of the used biological system, the presence of different cell types and the choice and number of mechanistic read-outs (Fig. 3). During the workshop state-of-the-art HCI studies performed either in academia, industry or regulatory research centers were discussed. Five examples of case studies (indicated in Fig. 3) with increasing levels of complexity are described below.

Case study A (unpublished observation of participants): The aim of the study was to investigate the potential liability of different drug candidates to induce toxicity in rat skeletal muscle. Rat skeletal muscle cell cultures were based on the L6 myoblast cell line. Immature myoblast cells were differentiated until fusion to myotubes was observed in vitro. Afterwards, differen-

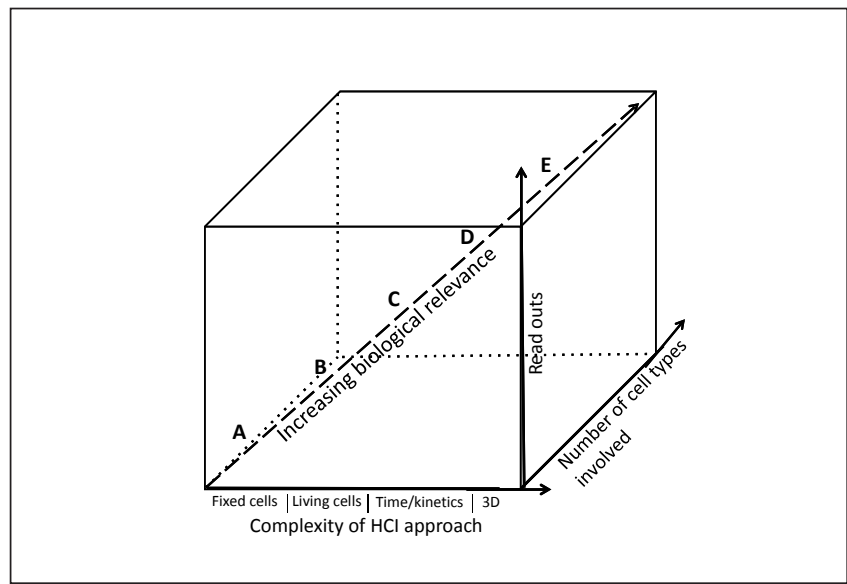

Fig. 3: Potential of $\mathrm{HCl}$

High content imaging assays can have different levels of complexity or numbers of read-outs, and cell types. The ideal $\mathrm{HCl}$ approach uses the simplest approach that is sufficient to answer the biological question. The points $A, B, C, D$ and $E$ refer to examples, i.e. the case studies described in the text.

tiated rat L6 skeletal muscle cells were treated with different compounds covering a wide range. Cells were treated for 5 days and cell death was measured by TUNEL assay as well as by assessment of the number of cells present in each well (objects count). To assess skeletal muscle specificity of the observed effects, rat fibroblasts were treated in parallel and cell death was measured in the same way as for rat skeletal muscle cells.

Case study B: The aim of the study was to investigate in $\mathrm{BALB} / \mathrm{c} 3 \mathrm{~T} 3$ cells mitochondrial toxicity by the non-invasive monitoring of bio-energetic activity and redox state using the endogenous fluorescing molecules nicotinamide adenine dinucleotide (NADH) and flavine adenine dinucleotide (FAD) (Bednarkiewicz et al., 2011; Rodrigues et al., 2011). The quantification of NADH and FAD auto-fluorescence can be used to determine whether mitochondria are in an active, resting, starved, or hypoxic/anoxic state. The transition between active and resting state can be used as a tool to detect the very early reversible changes in cell bioenergetics. If a compound induces injury the mitochondria will lose their membrane potential. This process will be detected by the conversion of mitochondrial NADH from its reduced fluorescing form to the non-fluorescing oxidized form. Positive controls for cytotoxicity were sodium lauryl sulfate and $\mathrm{HgCl}_{2}$. The time from the application of the compound to the drop in NADH fluorescence decreased with increasing concentrations of the compound. This allowed the establishment of highly sensitive concentration-response relationships for mitochondrial toxicity.

Case study C: The aim of the study was to investigate druginduced injury using parallel live cell time-lapse imaging of oxidative stress reporters in engineered HepG2 cells (Wink et al., 2014). In addition, because cellular stress responses typically follow cell perturbations at the sub-cellular organelle level, the oxidative stress monitoring was complemented with reporters for specific cell organelles to determine their morphometry and function. Oxidative stress was monitored using reporters for the 
oxidative stress sensor Keap1, the transcription factor Nrf2 and the antioxidant enzyme sulfiredoxin-1 (Srxn1). After exposure to the positive control iodoacetamide, Keap1 accumulation in foci (identified as autophagosomes). This was followed by the translocation of Nrf2 to the nucleus. Several hours later, these events were followed by a strong increase in the levels of Srxn1. Thus, the combination of oxidative stress and cell organelle reporter read-outs was able to detect different events of cellular malfunctioning on a single-cell basis, prior to the onset of cytotoxicity.

Case study D (unpublished observation of participants): The aim of the study was to investigate whether compounds induce liver toxicity by affecting either primary hepatocytes or Kupffer cells or both and in addition to measure Kupffer cell phagocytosis. Hepatocytes and Kupffer cells were co-cultured and treated with a compound at different concentrations for $48 \mathrm{~h}$. Then, Kupffer cells were stained for F4/80 and hepatocytes for albumin. Additionally, Kupffer cell phagocytic activity was assessed in parallel by the addition of latex beads labelled with a fluorochrome. Cytotoxicity was measured by using a combination of propidium iodide and calcein-AM. The assay differentiated direct cytotoxicity in hepatocytes or Kupffer cells and additionally could measure Kupffer cell phagocytosis by uptake of latex beads into Kupffer cells. The combination of the read-outs informed on complex interactions of hepatocytes and Kupffer cells with regard to their cell type specific functions.

Case study E: The aim of the study was to investigate if the in vitro assessment of multiple cardiomyocyte physiological parameters enables predictive and mechanistically interpretable evaluation of cardiotoxicity at high throughput level (Sirenko et al., 2013). Human iPSC-derived cardiomyocytes were exposed for $30 \mathrm{~min}$ or $24 \mathrm{~h}$ to 131 drugs (incl. positives and negatives). Fast kinetic imaging was used to monitor changes in cardiomyocyte function using intracellular $\mathrm{Ca}^{2+}$ flux read-outs synchronous with beating and cell viability. A number of physiological parameters of cardiomyocyte beating, such as beat rate, peak shape (amplitude, width, raise, decay, etc.) and regularity were collected using automated image analysis. Concentration-response profiles were evaluated using logistic modeling to derive a benchmark concentration (BMC). BMC values were used for cardiotoxicity classification and ranking of compounds. The assay showed that beat rate and several peak shape parameters were good predictors, while cell viability had poor classification accuracy. In addition, a toxicological prioritization index approach was applied to integrate and display data across many collected parameters, to derive "cardiosafety" ranking of tested compounds. Thus multiparametric functional screening of beating profiles allowed for cardiotoxicity hazard assessment and identification of specific patterns defining mechanism-specific effects.

\section{Current gaps and challenges for high content imaging approaches}

High content imaging technologies have advanced considerably over the last years. Technological developments that have facilitated these advances include the development of improved automated microscopes (auto-focusing, sample positioning) and increasingly sophisticated image analysis algorithms. Nevertheless there remain significant gaps and challenges to be overcome to fully exploit the potential of the technology in safety sciences (Zanella et al., 2010; Bickle, 2010).

\subsection{Technical limitations}

The applicability of imaging systems for more complex biological systems such as 3-dimensional cell models (e.g., floating spheroids) is still limited by the depth of light penetration and diffusion of probes. The requirement for attached cells is also still a limitation for routine applications and fluorescence activated cell sorting (FACS) is the preferred method in this case. Complications arise, e.g., when adherent cells detach during cell death processes (Leist et al., 1996; Falsig et al., 2004). Under such circumstances, microscopic methods need to include timelapse imaging with very complex quantification techniques and therefore biochemical methods are still superior.

The limited availability of reporters, probes and biosensors for the visualization and quantification of cell signaling pathways restricts the design of functional $\mathrm{HCI}$ assays. This also concerns the number of probes that can be introduced in a biological system and can be simultaneously measured and distinguished using different channels (e.g., based on signal wavelengths).

Standard HCI software is still limited with respect to the combination of selection criteria for cells. Often large numbers of cells are excluded in the analysis. For example, complex cells or cell phenotypes that are easily scored by semi-manual methods (Gerhardt et al., 2001; Volbracht et al., 1999; Hansson et al., 2000) are hard to recognize for the software. This applies often when cells undergo morphological changes, for example as they occur in phagocytosis assays (Hirt et al., 2000) or when using cytochrome c release as endpoint (Latta et al., 2000).

\subsection{Scientific relevance and standardization of the biological system}

For HCI, as for other analytical approaches, it is critical to select and characterize a biological system that is scientifically relevant for the purpose of the assay. The morphological (cell types, structures, receptors) and functional (signaling pathways, metabolism, transport) phenotype of the biological system must be sufficiently characterized to make sure it is relevant for the effects to be studied. For example, for the study of compounds that require cell-cell interactions or metabolism to exert their toxicity, a biological system with the appropriate cell types and metabolic capacity must be selected (Gantner et al., 1996). As safety sciences are moving towards mode-of-action investigations in increasingly complex biological systems, such characterization steps will become more important. Besides characterization, the biological system should be well standardized to guarantee the scientific relevance and reproducibility of the obtained results. Therefore, the health condition, purity and dynamic range of biological response of a biological system should be regularly controlled using reference compounds with a well known effect. Historical data on reference compounds can be used to define performance standards for biological systems and measurements (Wind and Stokes, 2010; Leist et al., 2010; Smirnova et al., 2014). 
Tab. 1: List of compiled reference compounds with well-known biological effects

\begin{tabular}{|l|l|}
\hline Examples for reference compounds & Effect \\
\hline Gambogic acid, camptothecin, staurosporine, actinomycin D & Apoptosis \\
\hline $\begin{array}{l}\text { Classical ETC inhibitors: Rotenone, antimycin A, oligomycin } \\
\text { Classical uncouplers: FCCP, CCCP } \\
\text { Others: troglitazone, simvastatin, valproic acid, amineptine }\end{array}$ & Mitochondrial respiration \\
\hline IL-1a, IL-1ß,TNF-a, PDGF & \\
\hline $\begin{array}{l}\text { PGA }, \text { sulforaphane, iodacetamide, 3H-1, 2-dithiole-3-thione (D3T), } \\
\text { tert-butylhydroquinone (tBHQ) }\end{array}$ & NF-KB signaling \\
\hline $\begin{array}{l}\text { SU6656, okadaic acid (phosphatase inhibitor), colchicine, NO-donors, } \\
\text { MG 132 (proteasome inhibitor) }\end{array}$ & Keap1/Nrf2 stress response \\
\hline Amiodarone, propranolol, citalopram & Phospholipidosis \\
\hline $\begin{array}{l}\text { Tunicamycin (perturbs protein glycosylation), thapsigargin (disruption of ER calcium), } \\
\text { brefeldin A (perturbs protein transport), } \\
\text { CsA, ATF-4, XBP1 }\end{array}$ & ER stress (ATF-4 responses, XBP1-responses) \\
\hline Menadione, tert-butylhydroperoxide & \\
\hline
\end{tabular}

\subsection{Lack of widely recognized reference compounds}

The dearth of widely recognized reference compounds to control the scientific relevance and technical reproducibility of HCI assays is one of the major gaps in the field. There is a need for a database with reference compounds that have a well-characterized effect on the phenotype or function of a certain biological system. These compounds would not only serve as internal assay control, but also provide the means to compare the cellular response across laboratories and institutions (Kadereit et al., 2012). An important role of such endpoint-specific control compounds (Leist et al., 2010) is to determine the specificity of the observed toxicity for a particular target or pathway. During the workshop, the participants compiled an example list of reference compounds for their respective assays (see Tab. 1) to initiate the process of closing this gap.

\subsection{Concentration issues}

A limitation for HCI and in vitro toxicity studies in general is that the true concentrations of a given test compound in a biological system are not known (Blaauboer et al., 2012). When a certain concentration (nominal) of a compound is added to an in vitro system, a part of the compound will be bound, e.g., to the proteins in the cell culture media (e.g., serum) and the plastic of the cell culture dish (Kramer et al., 2012). The compound that remains unbound will represent the free concentration to which the cell system is exposed (Fig. 4). For chronic toxicity studies the treatment protocol often includes the addition of multiple doses via changes of the cell culture media. Depending on the nature of the compound and the metabolic capacity of the biological system, the compound and/or its metabolites can accumulate in the cell system and lead to higher treatment concentrations than anticipated. This accumulative effect can result in toxicity over-predictions for a compound.

The distribution of a particular compound in the biological system is even more complex. Related to its physical-chemical properties (e.g., hydrophilic or lipophilic) a compound can bind to cell membranes, accumulate in the cytoplasm or in specific subcellular organelles. The distribution of compounds in different cell organelles is not well known, because measurements require highly sensitive technologies. Nonetheless, this type of information would be particularly valuable for the field of HCI because it allows the study of effects on subcellular structures (e.g., mitochondria, lysosome, ER). In addition, the presence of drug transport proteins such as P-glycoprotein (PGP), which can actively transport (extrusion) compounds

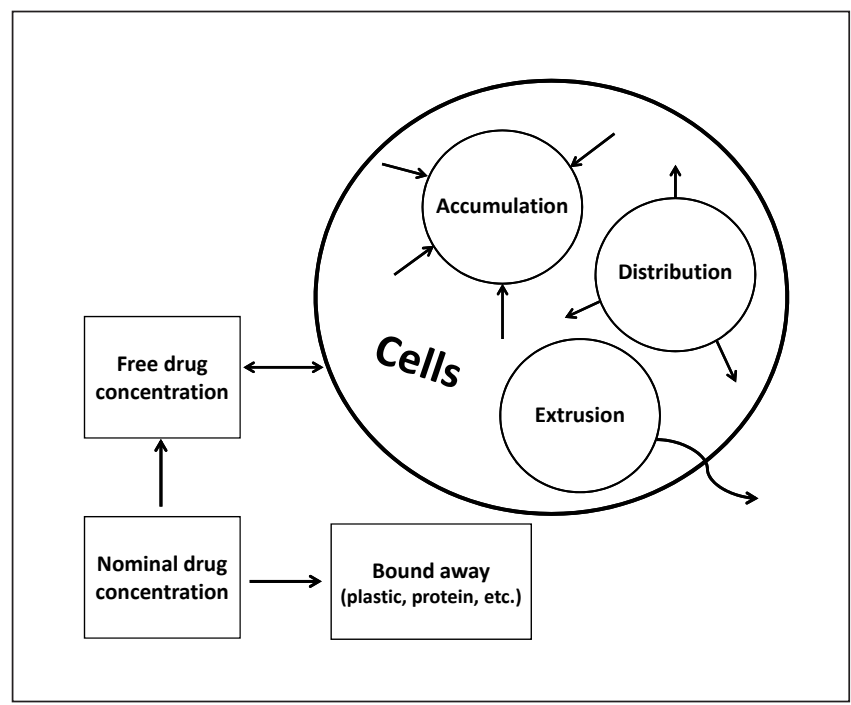

Fig. 4: Relationship between nominal compound concentrations in $\mathrm{HCl}$ assays and concentrations of test compounds in cells

When a nominal concentration of a compound is added to an in vitro system, a part of it will be bound and the cell is exposed to the unbound free concentration. The concentration of a compound in a cell or cell system will depend on its physical-chemical properties and the biological characteristics of the cell systems (e.g., cell metabolism and transport). 
out of a cell, plays a role in the distribution of a compound in a biological system. The technologies required to measure true concentrations of compounds in a cell or cell system (e.g., imaging or mass spectrometry) are still under development and not available for routine studies. Techniques that combine mass spectrometry and imaging techniques (matrix-assisted laser desorption/ionization, secondary ion mass spectrometry (SIMS) and nanoSIMS) are promising (Dollery, 2013). Because there is a major need to define true concentrations in in vitro systems, more efforts are required to develop and standardize the required technologies.

\subsection{Benchmarking of high content imaging data}

A particular added value of the high content imaging approach is that it allows comparisons of concentration-response relationships for multiple phenotypic and functional read-outs in a biological system (see Fig. 5). The concentrations that affect cell function can be distinguished from those that induce cytotoxicity. In a functional assay, the size of the off-set between functional endpoint and cytotoxicity is an important characteristic to demonstrate the relevance of the obtained results. A large off-set shows that a compound specifically affects cell function. Using reference compounds with a standardized offset in a biological system, a functional assay can be validated. The concentrations at which the in vitro read-outs are affected can be used as benchmark concentrations (BMC). These BMCs can also be established for different sub-populations of cells in a biological system or in different cell organelles (Veronika et al., 2009). Consequently, multiple concentration response-

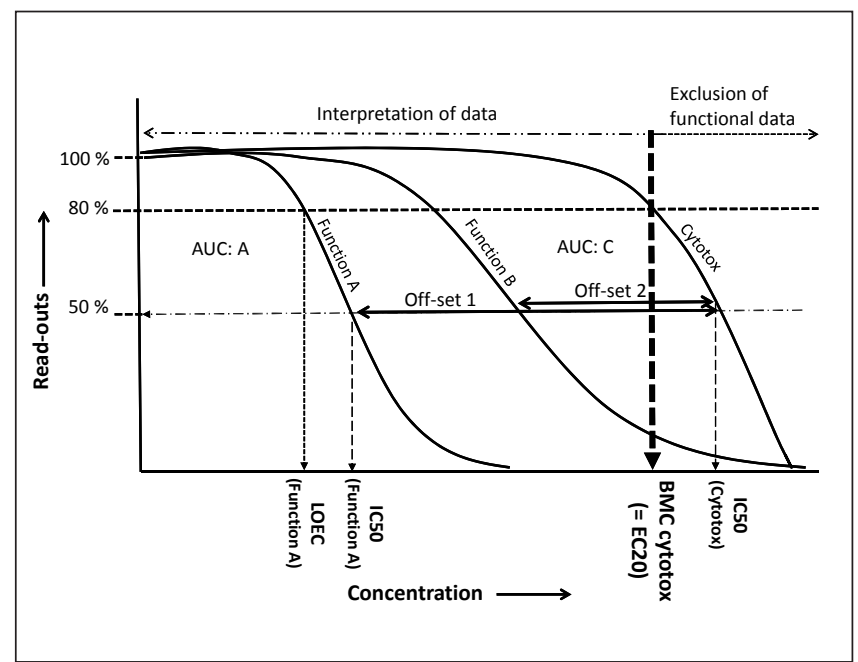

Fig. 5: The relationship between functional and cytotoxicity readouts of an $\mathrm{HCl}$ assay

The plotting of multiple concentration response curves from functional and cytotoxicity read-outs allows the determination of benchmark concentrations (BMC), such as the $\mathrm{EC}_{20}$. Also, the Lowest Observed Effect Concentration (LOEC) and $\mathrm{IC}_{50}$ concentrations can be determined and used. The benchmark response in the figure was set arbitrarily to $20 \%$, in other cases, 10 or $15 \%$ could be more relevant depending on the read-out parameters. curves can be plotted for different cell types or cell populations in a biological system. The in vitro benchmark concentrations for the multiple read-outs can also be combined, e.g., by calculation of ratios. For safety assessment, the in vitro benchmark concentrations can be extrapolated to a dose and compared to in vivo or clinical benchmarks (e.g., in biofluids or tissue). A big challenge for the use of benchmark concentrations from HCI assays is how to weigh the importance of the different read-outs.

\subsection{Imaging of dynamic responses}

Although the processes in a biological system are dynamic, most of the endpoints used in safety sciences are based on the strength of a perturbation instead of its dynamics. High content imaging in living biological systems using time-lapse microscopy can provide information on both the strength and dynamics (e.g., frequency) of biological responses over time. Because compounds can change the dynamics of biological processes instead of the strength, the study of dynamics can be essential for mode-of-action identifications. Figure 6 provides an example of a normal versus a toxicity response with an identical strength represented by the area under the curve (AUC 1 = AUC 2), but with different dynamics (frequency). The difference between these two responses would be identified by endpoints measuring their dynamics over time, but not by their strength (= average increase) at a given time point. Dynamics are particularly important for functional assays and they occur on very different time scales. For example, NF-KB translocation has a low frequency (hours) compared to calcium

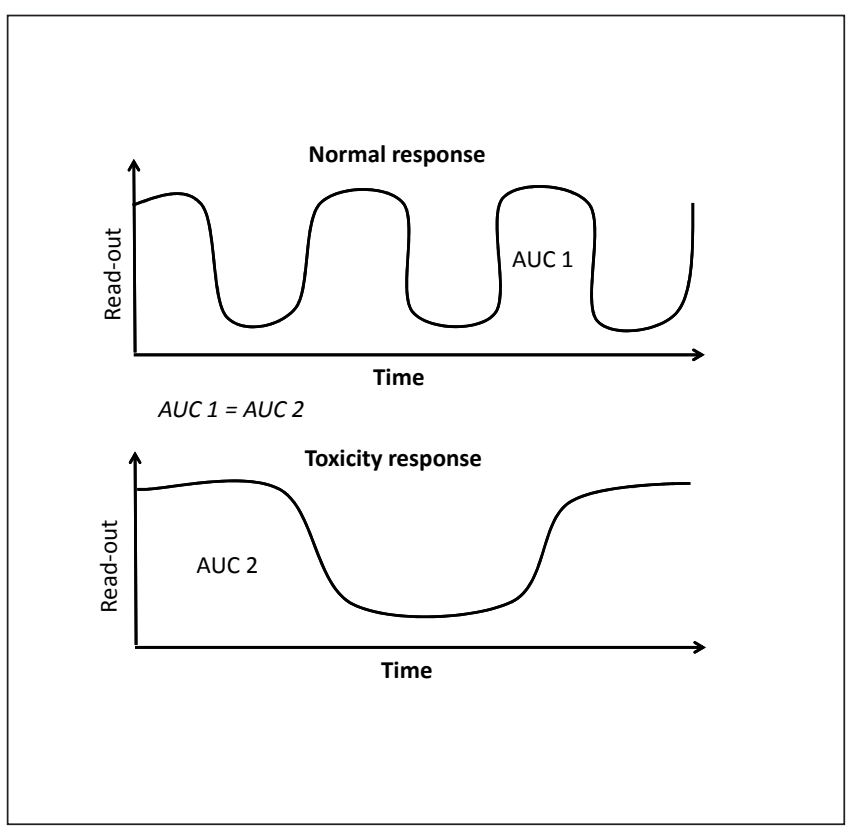

Fig. 6: Imaging of dynamic responses

The added value of imaging response dynamics is that it provides information on both the frequency and amplitude of a biological response. Although the amplitude of two responses can be identical in the area under the curve (AUC), their frequency can be changed by an exposure. 


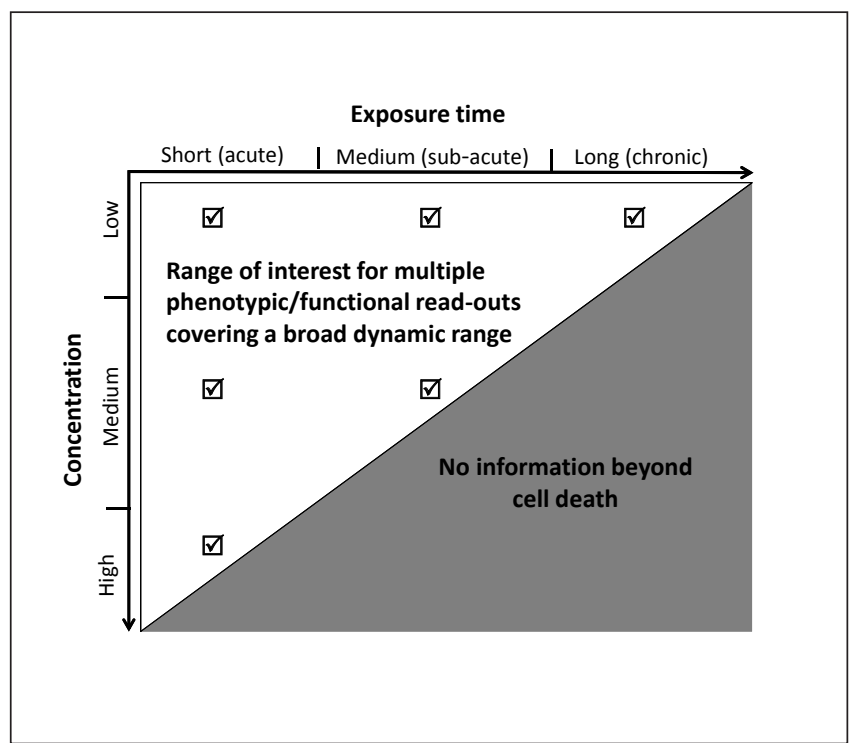

Fig. 7: Overview of exposure scenarios that can be addressed specifically (white) or that result in unspecific cell death (grey)

Phenotypic and functional read-outs within this range of interest can provide mechanistic insight into the response of a biological system after exposure to a compound.

fluxes (seconds). Therefore, it is important to consider the time resolutions of the functional read-outs during the design of an assay in order to pick up all the dynamics of the response. Another example where dynamics play an important role is cell cycle analysis, as different phases occur over time.

The range of interest in which the toxicity mechanisms of a compound can be studied is dependent on the time scale (acute or chronic effects) as well as the concentration range (Fig. 7). The range of interest starts with the biological system at homeostasis and ends at the induction of cell death, which provides no additional mechanistic information on MoA. Different exposure scenarios can yield broader information on toxicity than only a single standard approach, and the set of conditions needs to be adapted to the types of endpoints chosen.

\section{Quality control and performance standards}

Quality control measures and performance standards are a highly important but neglected area, not just for HCI but also for other modern approaches (Ramirez et al., 2013; Basketter et al., 2012; Leist et al., 2010).

A preparation of guidelines was highly recommended by the participants of the workshop to improve the quality and reproducibility of HCI data, and to facilitate comparison of data between institutions. As a first step, the participants proposed to establish guidance for the reporting of HCI studies in the scientific literature (Tab. 2). Currently, the settings of the instrumentation and details of data analysis are often not provided in publications. This makes it impossible to reproduce a study. Some basic guidance on scientific reporting would help to fully understand the design of assays and to reproduce results. A framework for quality control measures and performance standards discussed during the workshop is summarized in Table 3.

\section{Data analysis and integration of read-out parameters}

HCI can be used as (i) a hypothesis driven approach that aims to confirm a predefined MoA by the quantification of related mechanistic parameters or (ii) as an unsupervised hypothesis generating approach that aims to identify a mechanism/MoA by the unbiased quantitative screening of multiple mechanistic parameters that cover different MoAs. For the former approach, the levels of the predefined mechanistic parameters are measured and compared to identify statistically significant up or down regulations by a compound. To confirm the hypothesis (e.g., MoA), siRNA or pharmacological antagonists can be applied to test whether the toxicity occurs when the mechanism(s) is inhibited or blocked. The screening approach usually involves much larger datasets. Because the importance or weight of the different readout parameters is not know, it can be challenging to create a reduced index with the most relevant parameters. Unsupervised data mining techniques are often applied (e.g., principal component analysis or linear dis-

Tab. 2: Guidelines for the reporting of high content imaging results

\begin{tabular}{|l|l|}
\hline Aspect of the study & Information required \\
\hline Instrument settings & - All settings need documentation in a form that is platform-independent (as far as possible). \\
\hline Biological system & $\begin{array}{l}\text { - Biological relevance needs to be justified. } \\
- \text { Labeling procedures need comprehensive description. } \\
\end{array}$ \\
\hline Readout parameters & $\begin{array}{l}\text { - Scientific relevance needs justification and validation by control compounds. } \\
\text { - Dynamic range of measurement (time) needs full exploration. }\end{array}$ \\
\hline Image analysis & $\begin{array}{l}\text { - Define algorithms independent of commercial platform used. } \\
- \text { Inclusion and exclusion criteria for imaging targets with documentation by example images } \\
\text { need to be defined. }\end{array}$ \\
\hline Data analysis & $\begin{array}{l}\text { - Statistics need to be applied. } \\
\text { - Number of imaged targets (cells, organelles, pathways, etc.) needs to be documented. }\end{array}$ \\
\hline
\end{tabular}


Tab. 3: Overview of proposed quality control and performance standards

\begin{tabular}{|l|l|}
\hline Requirements & Proposed solutions \\
\hline Instrument calibration & $\begin{array}{l}\text { Control of the read-out settings and dynamic range of the assay using a standardized kit } \\
\text { that includes cells labeled for multiple parameters. }\end{array}$ \\
\hline Image analysis calibration & $\begin{array}{l}\text { Calibration of image analysis algorithms by the analysis of a set of widely accepted } \\
\text { reference images. }\end{array}$ \\
\hline Biological controls & $\begin{array}{l}\text { Control of the biological relevance, health status and dynamic response of the biological } \\
\text { system using a library of widely accepted positive and negative reference compounds. }\end{array}$ \\
\hline Toxicity controls & $\begin{array}{l}\text { Control of the specificity of the toxic effects for a particular target (e.g., receptor, } \\
\text { cell type, organelle, organ) using reference compounds, gene silencing approaches or } \\
\text { pharmacological inhibitors. }\end{array}$ \\
\hline Data controls & \begin{tabular}{l} 
Deposit of data in databases and opportunity for review by independent labs. \\
\hline Data handling and analysis guidelines
\end{tabular} \\
\hline $\begin{array}{l}\text { Guidelines for data storage, analysis and sharing via databases should be developed, } \\
\text { giving transparency as to which guidelines have been followed. }\end{array}$ \\
\hline Performance standards & $\begin{array}{l}\text { Establishment of performance standards based on historical data on: } \\
- \text { Number of cells that need to be analyzed } \\
- \text { Dynamic range } \\
- \text { Reproducibility of results } \\
- \text { Sensitivity and specificity for reference compounds }\end{array}$ \\
\hline
\end{tabular}

criminant analysis) to identify the parameters with the largest contribution or weight. The next challenge is the integration of the identified parameters to generate a hypothesis on the MoA of a compound. Data integration software coupled with databases on fundamental biological processes can be used to correlate the response of the individual parameters and link them in functional networks and cell signaling processes. To support the analysis and integration of HCI data it would be useful to establish reference databases with information on the biological relevance and mechanistic relationships between read-out parameters. Such a database could be linked to HCI software that automatically integrates and links multiple read-out parameters with biological information to confirm or generate a hypothesis on the MoA of a compound.

\section{Integration of high content imaging with other technologies}

Supported by the advances in informatics and data analysis technologies, the field of safety sciences is moving towards a systems biology approach that aims to integrate data from different technologies to obtain a systems level understanding of the mechanistic pathways underlying cell adaptation and toxicity (van Vliet, 2011; Hartung et al., 2012). The focus in the area of systems biology is mostly on omics technologies because they provide comprehensive information on the genome, proteome or metabolome of a biological system (Waldmann et al., 2014; Wink et al., 2014; Sturla et al., 2014). However, information on the dynamics over time can be required to understand the MoA of a compound. Therefore, HCI can be a valuable technology to complement the systems biology approach with information on the spatial distribution and dynamics of biological processes and responses (see Fig. 8). Omics tech- nologies are particularly useful for the identification of genes, proteins and metabolites involved in the mechanistic pathways underlying cell defense, adaptation and toxicity. High content imaging in living cells using time-lapse microscopy can be used to monitor the spatial distribution and dynamics of the identified pathways to identify the switch-points between biological processes, e.g., from homeostasis, to the activation of

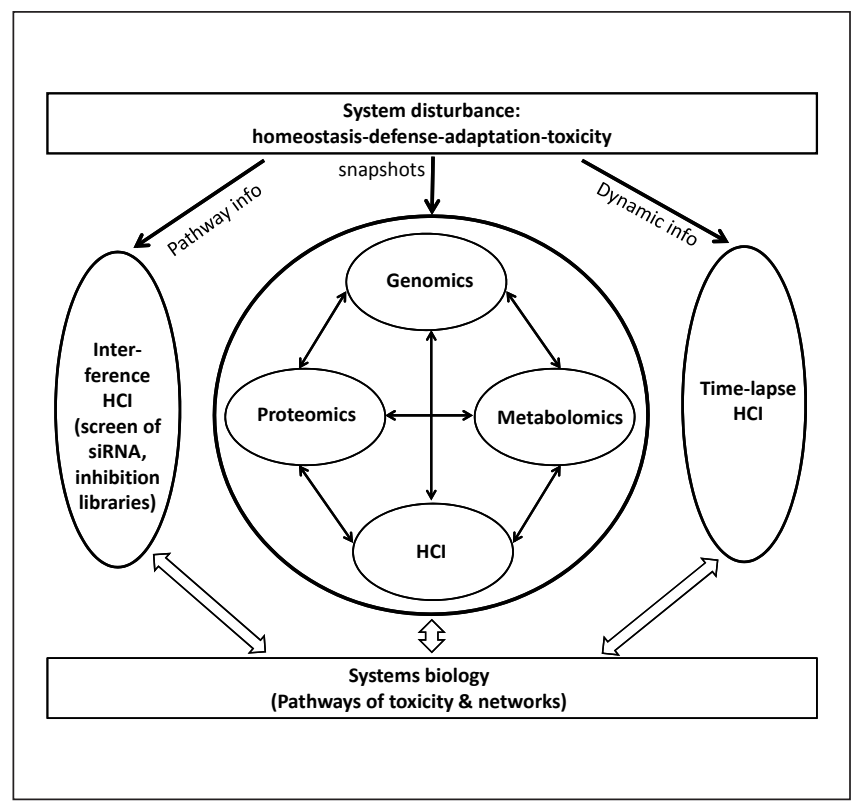

Fig. 8: Integration of $\mathrm{HCl}$ with other technologies

Time-lapse high content imaging in living cells and interference high content screening using siRNA can complement the systems biology approach with information on the spatial distribution and dynamics of pathways and by validating the pathways of toxicity. 
cell defense mechanisms, cellular adaptation and induction of toxicity. In addition the high content screening based on siRNA libraries allows the confirmation of pathways for a toxic effect (Fredriksson et al., 2011; Verissimo et al., 2012), identification of alternate pathways and the interaction between different pathways in the system. The inclusion of dynamic information (monitoring of read-out levels over exposure time and concentration range) into the systems biology approach also supports the modeling of benchmark concentrations for safety assessment.

\section{Future perspectives}

\subsection{Future potential of high content imaging for safety sciences}

Although high content imaging currently plays an important role in safety sciences (Fig. 9), the application of the technology is expected to increase further, as safety studies are increasingly focused on MoA (Andersen and Krewski, 2009). At present, HCI technologies are often used to patch knowledge gaps (e.g., to confirm the mechanism of an in vivo effect) using tailored multi-parametric and functional assays. In fact, general scientific progress in toxicology is still largely based on the patching of knowledge gaps and replacement of a single technology with an improved one, despite suggestions to re-think the overall approach and re-design it from scratch (Leist et al., 2008, 2012; Hartung, 2009; Basketter et al., 2012). More work is required on how to integrate HCI data with data from other assays and other emerging technologies (e.g., omics, in silico tools, organ-on-a-chip) to create a systems biology approach. Moreover the integration of HCI data with information on free and cellular concentrations in the biological system (e.g., using SIMS imaging technologies) would be particularly promising, as it could generate very accurate information on the concentra-

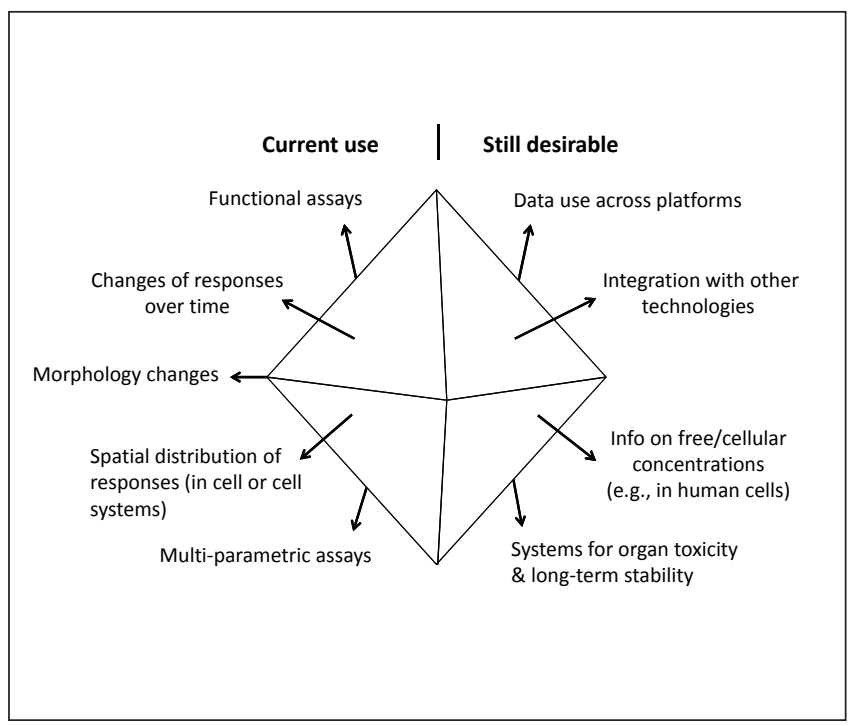

Fig. 9: State of the art and future developments of $\mathrm{HCl}$ in the field of safety sciences and drug discovery tions that induce mechanisms of cell defense, adaptation and toxicity in different compartments of a cell, cell type or cell system. Complex biological systems, such as organ-on-a-chip models that closely reproduce the in vivo microenvironment, will offer new opportunities for the study of long-term toxicity of low concentrations in organ and multiple organ systems. Because these systems provide novel opportunities to stimulate the organ using mechanic force or pharmacological tools, they will create opportunities to image specific perturbations under controlled conditions.

\subsection{Inclusion of high content imaging in the design of testing batteries and strategies}

It is generally recognized that the safety of a compound cannot be based on a single in vitro assay. Therefore, scientists are working on the design of testing batteries and coupled strategies (Hartung et al., 2013). A testing strategy involves, e.g., tiered testing with interim decisions between assays, for example by testing only negative or positive compounds (hits) in the next assay. Due to the variety of phenotypic and functional endpoints that can be measured, HCI assays can be valuable for the design of testing strategies. Tailored HCI assays based an animal or human cell models could be strategically combined to identify hits for a number of pre-defined phenotypic and functional endpoints (see Fig. 10). For example, for drug development a testing strategy for different target organ functions at non-cytotoxic concentrations could be designed for the safety screening and ranking of lead compounds. The strategy design could be based on functional read-outs for liver toxicity (e.g., phospholipidosis, cholestasis, steatosis), neurotoxicity (e.g., neurite outgrowth, neurotransmission) and cardiotoxicity (e.g., contractility, $\mathrm{Ca}^{2+}$ flux readouts). Compounds that affect a functional read-out could be identified as a hit and be further investigated. The concentration-dependence of the different endpoints could also give first indications on organ toxicity.

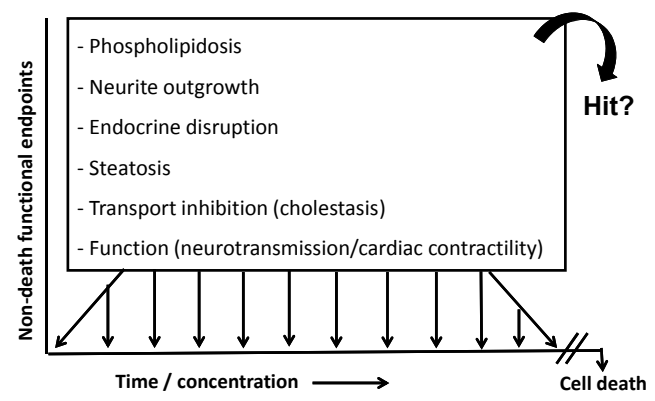

Fig. 10: Tailored high content imaging assays can be combined in a testing strategy to efficiently identify hits for multiple functional endpoints

Different functional perturbations can be measured by $\mathrm{HCl}$ at concentrations or exposure conditions that do not trigger cell death. 

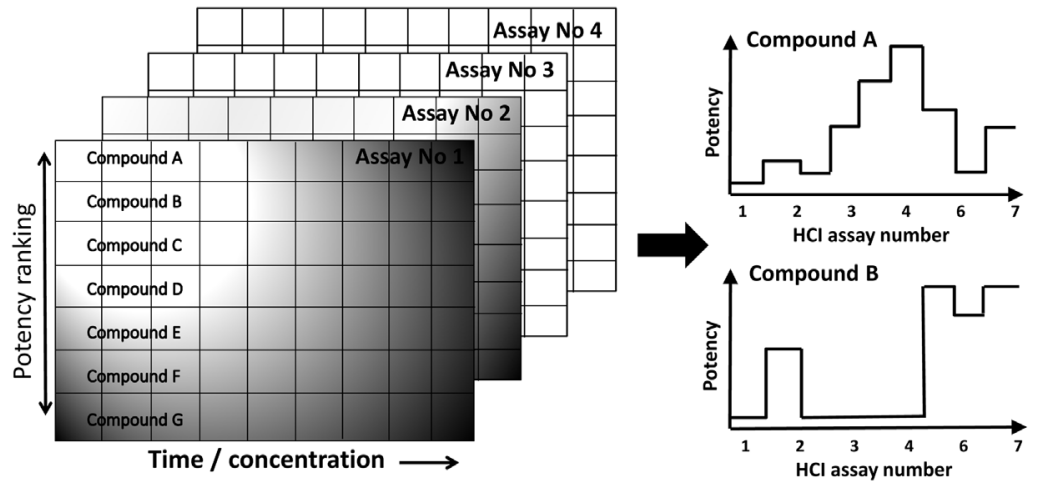

Fig. 11: Use of $\mathrm{HCl}$ profiles of multiple assays across time and concentrations for compound profiling and read across

Compounds can be grouped according to mechanistic similarity and be ranked within groups for potency.

\subsection{Development of $\mathrm{HCl}$ computational database systems for "Big Data"}

$\mathrm{HCI}$ data can be used to establish toxicity profiles for compounds. The profiles within a research institution or among different institutions could be gathered in computational database systems (Big Data) according to strict guidelines for data relevance and quality. Such efforts have already been initiated by ToxCast (Kleinstreuer et al., 2014), the Tox21 programs (Zang et al., 2013) and within the ToxBank project of SEURAT-1 (toxbank.net). Once the database contains a critical number of compounds and read-out parameters (incl. reference compounds for specific MoA and organ toxicities) the HCI profiles could be compared for the hierarchical ranking of new compounds according to their potency, hazard, efficacy or MoA (see Fig. 11) in a quantitative read across approach. In addition, the multiple read-outs could be ranked according to their specificity and sensitivity for specific toxic effects. Such a database would be particularly useful for industry and regulatory bodies to prioritize compounds and read-out parameters for safety assessment and drug development. This could form the basis for a new approach to the study of systemic and long-term chronic effects at low concentrations (e.g., liver toxicity). Moreover, animal studies could be made more efficient by the pre-selection of highly specific and sensitive read-out parameters. The database could also be used to predict the mechanisms or classify unknown compounds, by comparing their $\mathrm{HCI}$ profile to the profiles of the compounds in the database. Besides HCI data other types of information could eventually be introduced in the database, e.g., in silico data based on physiochemical or pharmacokinetic properties of compounds, which also determine their bioavailability and the interaction with cellular structures (binding to membranes, receptors, proteins, cell organelles).

\subsection{Regulatory acceptance of high content imaging}

The application of high content imaging in safety sciences would significantly advance, if its results were also used for regulatory purposes. To achieve this, HCI assays would need to be validated and accepted by regulatory agencies. Ideally, the regulators would gain experience with the technology themselves to build confidence in the information it can provide. As an initial step, it may be useful to integrate $\mathrm{HCI}$ technologies into the regulatory framework for MoA identifications. This could be done, for example, by using HCI readouts to link molecular level data to the resulting alteration in cellular function and phenotype. The information on MoA and compound behavior can also support the weight of evidence approach for regulatory decision-making. At this point it is most crucial to design guidance for the quality assurance and validation of $\mathrm{HCI}$ technologies.

\section{Conclusions}

With the current focus of toxicology on the understanding of toxicity pathways in (human) cell systems and mechanistic safety assessment, the role of HCI technologies is likely to increase further (Leist et al., 2008; Andersen and Krewski, 2009; Krewski et al., 2010; Berg et al., 2011; van Vliet, 2011). To fully exploit the potential of $\mathrm{HCI}$, there are still some remaining gaps and challenges to be overcome (Box 2). To increase the scientific relevance of HCI data for the in vivo and human situation, the technology must be tailored for the analysis of more complex biological systems such as 3D cell models (Wenzel et al., 2014) and human stem cell models (Barbaric et al., 2010; Sherman et al., 2011). For this, it is also necessary to develop additional probes and biosensors to label, monitor and quantify multiple functional processes in biological systems without interference. Moreover, data quality and reproducibility would benefit from the establishment of widely accepted control measures and performance standards in the field. For the design of HCI assays it is important to test the scientific relevance and stability of the biological system using reference compounds that induce wellcharacterized perturbations. At the same time more knowledge is required on the exact concentrations of compounds (free and bound) in cell culture systems and their distribution at the subcellular level. Ideally the concentration of compounds in cells or cell organelles could be quantified during HCI studies to allow more accurate predictions of in vitro benchmark concentration 
for toxicity or efficacy of drug compounds. Because HCI provides concentration-response information on multiple phenotypic and functional read-outs, novel composite endpoints may be established to allow more specific predictions (Perkins et al., 2013). For compounds that require information on dynamics or spatial distribution for safety assessment (e.g., temporary morphometric effects or metabolism related effects), HCI data using time-lapse microscopy can be applied to generate dynamic and spatial profiles of biological responses. As the extrapolation of in vitro data from traditional single quantitative readouts is already a challenging task, more research is required on how data on dynamics and spatial distribution could be integrated.

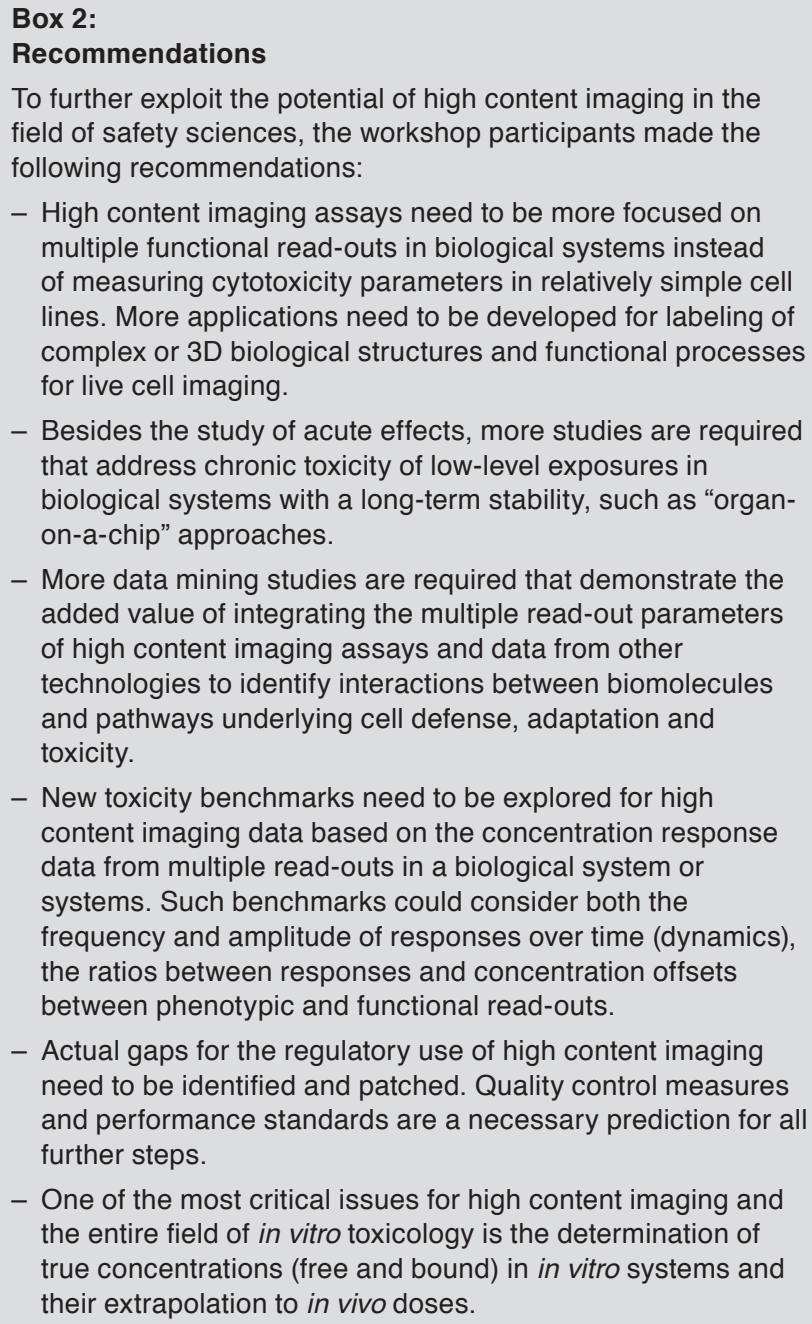

- High content imaging assays need to be more focused on multiple functional read-outs in biological systems instead of measuring cytotoxicity parameters in relatively simple cell lines. More applications need to be developed for labeling of complex or 3D biological structures and functional processes for live cell imaging.

- Besides the study of acute effects, more studies are required that address chronic toxicity of low-level exposures in biological systems with a long-term stability, such as "organon-a-chip" approaches.

- More data mining studies are required that demonstrate the added value of integrating the multiple read-out parameters of high content imaging assays and data from other technologies to identify interactions between biomolecules and pathways underlying cell defense, adaptation and toxicity.

- New toxicity benchmarks need to be explored for high content imaging data based on the concentration response data from multiple read-outs in a biological system or systems. Such benchmarks could consider both the frequency and amplitude of responses over time (dynamics), the ratios between responses and concentration offsets between phenotypic and functional read-outs.

- Actual gaps for the regulatory use of high content imaging need to be identified and patched. Quality control measures and performance standards are a necessary prediction for all further steps.

- One of the most critical issues for high content imaging and the entire field of in vitro toxicology is the determination of true concentrations (free and bound) in in vitro systems and their extrapolation to in vivo doses.

\section{References}

Abraham, V. C., Taylor, D. L. and Haskins, J. R. (2004). High content screening applied to large-scale cell biology. Trends Biotechnol 22, 15-22. http://dx.doi.org/10.1016/j. tibtech.2003.10.012
Abraham, V. C., Towne, D. L., Waring, J. F. et al. (2008). Application of a high-content multiparameter cytotoxicity assay to prioritize compounds based on toxicity potential in humans. J Biomol Screen 13, 527-537. http://dx.doi. org/10.1177/1087057108318428

Andersen, M. E. and Krewski, D. (2009). Toxicity testing in the $21^{\text {st }}$ century: bringing the vision to life. Toxicol Sci 107, 324330. http://dx.doi.org/10.1093/toxsci/kfn255

Baker, M. (2011). Tissue models: a living system on a chip. $\mathrm{Na}$ ture 471, 661-665. http://dx.doi.org/10.1038/471661a

Barbaric, I., Gokhale, P. J. and Andrews, P. W. (2010). Highcontent screening of small compounds on human embryonic stem cells. Biochem Soc Trans 38, 1046-1050. http://dx.doi. org/10.1042/BST0381046

Basketter, D. A., Clewell, H., Kimber, I. et al. (2012). A roadmap for the development of alternative (non-animal) methods for systemic toxicity testing $-\mathrm{t}^{4}$ report. ALTEX 29, 3-91.

Bednarkiewicz, A., Rodrigues, R. M. and Whelan, M. P. (2011). Non-invasive monitoring of cytotoxicity based on kinetic changes of cellular autofluorescence. Toxicol In Vitro 25, 2088-2094. http://dx .doi.org/10.1016/j.tiv.2011.09.008

Benedetti, G., Fredriksson, L., Herpers, B. et al. (2013). TNFalpha-mediated NF-kappaB survival signaling impairment by cisplatin enhances JNK activation allowing synergistic apoptosis of renal proximal tubular cells. Biochem Pharmacol 85, 274-286. http://dx.doi.org/10.1016/j.bcp.2012.10.012

Berg, N., De Wever, B., Fuchs, H. W. et al. (2011). Toxicology in the $21^{\text {st }}$ century - working our way towards a visionary reality. Toxicol In Vitro 25, 874-881. http://dx .doi.org/10.1016/j. tiv.2011.02.008

Bickle, M. (2010). The beautiful cell: high-content screening in drug discovery. Anal Bioanal Chem 398, 219-226. http:// dx.doi.org/10.1007/s00216-010-3788-3

Blaauboer, B. J., Boekelheide, K., Clewell, H. J. et al. (2012). The use of biomarkers of toxicity for integrating in vitro hazard estimates into risk assessment for humans. ALTEX 29, 411-425.

Buchser, W., Collins, M., Garyantes, T. et al. (2004). Assay development guidelines for image-based high content screening, high content analysis and high content imaging. http:// dx.doi.org/NBK100913

Dollery, C. T. (2013). Intracellular drug concentrations. Clin Pharmacol Ther 93, 263-266. http://dx.doi.org/10.1038/ clpt.2012.240

Dragunow, M. (2008). High-content analysis in neuroscience. Nat Rev Neurosci 9, 779-788. http://dx.doi.org/10.1038/ nrn2492

Falsig, J., Porzgen, P., Lotharius, J. et al. (2004). Specific modulation of astrocyte inflammation by inhibition of mixed lineage kinases with CEP-1347. J Immunol 173, 2762-2770. http://dx.doi.org/173/4/2762

Földes, G. and Mioulane, M. (2013). High-content imaging and analysis of pluripotent stem cell-derived cardiomyocytes. Methods Mol Biol 1052, 29-39. http://dx.doi. org/10.1007/7651_2013_25 
Fredriksson, L., Herpers, B., Benedetti, G. et al. (2011). Diclofenac inhibits tumor necrosis factor-alpha-induced nuclear factor-kappaB activation causing synergistic hepatocyte apoptosis. Hepatology 53, 2027-2041. http://dx.doi.org/10.1002/ hep. 24314

Gantner, F., Leist, M., Kusters, S. et al. (1996). T cell stimulusinduced crosstalk between lymphocytes and liver macrophages results in augmented cytokine release. Exp Cell Res 229, 137-146. http://dx.doi.org/10.1006/excr.1996.0351

Gerhardt, E., Kugler, S., Leist, M. et al. (2001). Cascade of caspase activation in potassium-deprived cerebellar granule neurons: targets for treatment with peptide and protein inhibitors of apoptosis. Mol Cell Neurosci 17, 717-731. http://dx.doi. org/10.1006/mcne.2001.0962

Giuliano, K. A., DeBiasio, R. L., Dunlay, R.T. et al. (1997). High-Content Screening: A new approach to easing key bottlenecks in the drug discovery process. J Biomol Screen 2, 249-259.

Giuliano, K. A., Haskins, J. R. and Taylor, D. L. (2003). Advances in high content screening for drug discovery. Assay Drug Dev Technol 1, 565-577. http://dx.doi. org/10.1089/154065803322302826

Hansson, O., Castilho, R. F., Kaminski Schierle, G. S. et al. (2000). Additive effects of caspase inhibitor and lazaroid on the survival of transplanted rat and human embryonic dopamine neurons. Exp Neurol 164, 102-111. http://dx.doi. org/10.1006/exnr.2000.7406

Harrill, J. A., Robinette, B. L., Freudenrich, T. et al. (2013). Use of high content image analyses to detect chemical-mediated effects on neurite sub-populations in primary rat cortical neurons. Neurotoxicology 34, 61-73. http://dx.doi.org/10.1016/j. neuro.2012.10.013

Hartung, T. (2009). A toxicology for the $21^{\text {st }}$ century - mapping the road ahead. Toxicol Sci 109, 18-23. http://dx.doi. org/10.1093/toxsci/kfp059

Hartung, T., van Vliet, E., Jaworska, J. et al. (2012). Systems toxicology. ALTEX 29, 119-128.

Hartung, T., Luechtefeld, T., Maertens, A. et al. (2013). Integrated testing strategies for safety assessments. ALTEX 30, 3-18.

Henn, A., Lund, S., Hedtjarn, M. et al. (2009). The suitability of BV2 cells as alternative model system for primary microglia cultures or for animal experiments examining brain inflammation. ALTEX 26, 83-94.

Henn, A., Kirner, S. and Leist, M. (2011). TLR2 hypersensitivity of astrocytes as functional consequence of previous inflammatory episodes. J Immunol 186, 3237-3247. http:// dx.doi.org/10.4049/jimmunol.1002787

Herpers, B. and van de Water, B. (2013). High content imaging-based screening for cellular toxicity pathways, in highthroughput screening methods in toxicity testing (ed. P. Steinberg). Hoboken, NJ, USA: John Wiley \& Sons, Inc.

Hirt, U.A., Gantner, F. and Leist, M. (2000). Phagocytosis of nonapoptotic cells dying by caspase-independent mechanisms. $J$ Immunol 164, 6520-6529. http://dx.doi.org/ji_v164n12p6520

Huh, D., Hamilton, G. A. and Ingber, D. E. (2011). From 3D cell culture to organs-on-chips. Trends Cell Biol 21, 745-754. http://dx.doi.org/10.1016/j.tcb.2011.09.005

Kadereit, S.,Zimmer, B., van Thriel, C. et al. (2012). Compound selection for in vitro modeling of developmental neurotoxicity. Front Biosci (Landmark Ed) 17, 2442-2460. http://dx.doi. org/4064

Kim, M. J., Lee, S. C., Pal, S. et al. (2011). High-content screening of drug-induced cardiotoxicity using quantitative single cell imaging cytometry on microfluidic device. Lab Chip 11, 104-114. http://dx.doi.org/10.1039/c0lc00110d

Kim, J. A., Han, E., Eun, C. J. et al. (2012). Real-time concurrent monitoring of apoptosis, cytosolic calcium, and mitochondria permeability transition for hypermulticolor high-content screening of drug-induced mitochondrial dysfunction-mediated hepatotoxicity. Toxicol Lett 214, 175-181. http://dx.doi. org/10.1016/j.toxlet.2012.08.027

Kleinstreuer, N. C., Yang, J., Berg, E. L. et al. (2014). Phenotypic screening of the ToxCast chemical library to classify toxic and therapeutic mechanisms. Nat Biotechnol 32, 583591. http://dx.doi.org/10.1038/nbt.2914

Kramer, N. I., Krismartina, M., Rico-Rico, A. et al. (2012). Quantifying processes determining the free concentration of phenanthrene in Basal cytotoxicity assays. Chem Res Toxicol 25, 436-445. http://dx.doi.org/10.1021/tx200479k

Krausz, E. (2007). High-content siRNA screening. Mol Biosyst 3, 232-240. http://dx.doi.org/10.1039/b616187c

Krewski, D., Acosta, D., Jr., Andersen, M. et al. (2010). Toxicity testing in the $21^{\text {st }}$ century: A vision and a strategy. $J$ Toxicol Environ Health B Crit Rev 13, 51-138. http://dx.doi. org/10.1080/10937404.2010.483176

Krug, A. K., Balmer, N. V., Matt, F. et al. (2013). Evaluation of a human neurite growth assay as specific screen for developmental neurotoxicants. Arch Toxicol 87, 2215-2231. http:// dx.doi.org/10.1007/s00204-013-1072-y

Kuegler, P. B., Baumann, B. A., Zimmer, B. et al. (2012). GFAPindependent inflammatory competence and trophic functions of astrocytes generated from murine embryonic stem cells. Glia 60, 218-228. http://dx.doi.org/10.1002/glia.21257

Latta, M., Kunstle, G., Leist, M. et al. (2000). Metabolic depletion of ATP by fructose inversely controls CD95- and tumor necrosis factor receptor 1-mediated hepatic apoptosis. J Exp Med 191, 1975-1985.

Leist, M., Raab, B., Maurer, S. et al. (1996). Conventional cell culture media do not adequately supply cells with antioxidants and thus facilitate peroxide-induced genotoxicity. Free Radic Biol Med 21, 297-306. http://dx.doi.org/0891584996000457

Leist, M., Hartung, T. and Nicotera, P. (2008). The dawning of a new age of toxicology. ALTEX 25, 103-114.

Leist, M., Efremova, L. and Karreman, C. (2010). Food for thought ... considerations and guidelines for basic test method descriptions in toxicology. ALTEX 27, 309-317.

Leist, M., Lidbury, B. A., Yang, C. et al. (2012). Novel technologies and an overall strategy to allow hazard assessment and risk prediction of chemicals, cosmetics, and drugs with animal-free methods. ALTEX 29, 373-88. 
Lotharius, J., Falsig, J., van Beek, J. et al. (2005). Progressive degeneration of human mesencephalic neuron-derived cells triggered by dopamine-dependent oxidative stress is dependent on the mixed-lineage kinase pathway. J Neurosci 25, 6329-6342. http://dx.doi.org/25/27/6329

Lund, S., Porzgen, P., Mortensen, A. L. et al. (2005). Inhibition of microglial inflammation by the MLK inhibitor CEP-1347. J Neurochem 92, 1439-1451. http://dx.doi.org/JNC3014

Massoud, T. F. and Gambhir, S. S. (2003). Molecular imaging in living subjects: seeing fundamental biological processes in a new light. Genes Dev 17, 545-580. http://dx.doi.org/10.1101/ $\operatorname{gad} .1047403$

Mohamed, B. M., Verma, N. K., Prina-Mello, A. et al. (2011). Activation of stress-related signalling pathway in human cells upon $\mathrm{SiO} 2$ nanoparticles exposure as an early indicator of cytotoxicity. J Nanobiotechnology 9, 29. http://dx.doi. org/10.1186/1477-3155-9-29

Mulji, A., Haslam, C., Brown, F. et al. (2012). Configuration of a high-content imaging platform for hit identification and pharmacological assessment of JMJD3 demethylase enzyme inhibitors. J Biomol Screen 17, 108-120. http://dx.doi. org/10.1177/1087057111418229

NRC - National Research Council (2007). Toxicity Testing in the $21^{\text {st }}$ Century: A Vision and a Strategy. Washington, DC, USA: National Academy Press.

O'Brien, P. J., Irwin, W., Diaz, D. et al. (2006). High concordance of drug-induced human hepatotoxicity with in vitro cytotoxicity measured in a novel cell-based model using high content screening. Arch Toxicol 80, 580-604. http://dx.doi. org/10.1007/s00204-006-0091-3

Perkins, E. J.,Ankley, G. T., Crofton, K. M. et al. (2013). Current perspectives on the use of alternative species in human health and ecological hazard assessments. Environ Health Perspect 121, 1002-1010. http://dx.doi.org/10.1289/ehp.1306638

Persson, M., Loye, A. F., Mow, T. et al. (2013). A high content screening assay to predict human drug-induced liver injury during drug discovery. J Pharmacol Toxicol Methods 68, 302313. http://dx.doi.org/10.1016/j.vasen.2013.08.001

Ramirez, T., Daneshian, M., Kamp, H. et al. (2013). Metabolomics in toxicology and preclinical research. ALTEX 30, 209-225.

Rodrigues, R. M., Macko, P., Palosaari, T. et al. (2011). Autofluorescence microscopy: A non-destructive tool to monitor mitochondrial toxicity. Toxicol Lett 206, 281-288. http://dx.doi. org/10.1016/j.toxlet.2011.06.025

Schildknecht, S., Karreman, C., Poltl, D. et al. (2013). Generation of genetically-modified human differentiated cells for toxicological tests and the study of neurodegenerative diseases. ALTEX 30, 427-444.

Scholz, D., Chernyshova, Y. and Leist, M. (2013). Control of Abeta release from human neurons by differentiation status and RET signaling. Neurobiol Aging 34, 184-199. http:// dx.doi.org/10.1016/j.neurobiolaging.2012.03.012

Shariff, A., Kangas, J., Coelho, L. P. et al. (2010). Automated image analysis for high-content screening and analysis. J Biomol Screen 15, 726-734. http://dx.doi. org/10.1177/1087057110370894

Sherman, S. P., Alva, J. A., Thakore-Shah, K. et al. (2011). Human pluripotent stem cells: the development of high-content screening strategies. Methods Mol Biol 767, 283-295. http:// dx.doi.org/10.1007/978-1-61779-201-4_21

Sirenko, O., Cromwell, E. F., Crittenden, C. et al. (2013). Assessment of beating parameters in human induced pluripotent stem cells enables quantitative in vitro screening for cardiotoxicity. Toxicol Appl Pharmacol 273, 500-507. http://dx.doi. org/10.1016/j.taap.2013.09.017

Smirnova, L., Hogberg, H. T., Leist, M. et al. (2014). Developmental neurotoxicity - challenges in the $21^{\text {st }}$ century and in vitro opportunities. ALTEX 31, 129-156. http://dx.doi.org/ http://dx.doi.org/10.14573/altex.1403271

Stiegler, N. V., Krug, A. K., Matt, F. et al. (2011). Assessment of chemical-induced impairment of human neurite outgrowth by multiparametric live cell imaging in high-density cultures. Toxicol Sci 121, 73-87. http://dx.doi.org/10.1093/toxsci/ kfr034

Sturla, S. J., Boobis, A. R., FitzGerald, R. E. et al. (2014). Systems toxicology: From basic research to risk assessment. Chem Res Toxicol 27, 314-329. http://dx.doi.org/10.1021/ tx400410s

Tolosa, L., Pinto, S., Donato, M. T. et al. (2012). Development of a multiparametric cell-based protocol to screen and classify the hepatotoxicity potential of drugs. Toxicol Sci 127 , 187-198. http://dx.doi.org/10.1093/toxsci/kfs083

Trask, O. J., Jr., Moore, A. and LeCluyse, E. L. (2014). A micropatterned hepatocyte coculture model for assessment of liver toxicity using high-content imaging analysis. Assay Drug Dev Technol 12, 16-27. http://dx.doi.org/10.1089/adt.2013.525

van Vliet, E. (2011). Current standing and future prospects for the technologies proposed to transform toxicity testing in the $21^{\text {st }}$ century. ALTEX 28, 17-44.

Verissimo, C. S., Cheng, S., Puigvert, J. C. et al. (2012). Combining doublecortin-like kinase silencing and vinca alkaloids results in a synergistic apoptotic effect in neuroblastoma cells. J Pharmacol Exp Ther 342, 119-130. http://dx.doi. org/10.1124/jpet.111.188813

Veronika, M., Evans, J., Matsudaira, P. et al. (2009). Sub-population analysis based on temporal features of high content images. BMC Bioinformatics 10, Suppl 15, S4. http://dx.doi. org/10.1186/1471-2105-10-S15-S4

Volbracht, C., Leist, M. and Nicotera, P. (1999). ATP controls neuronal apoptosis triggered by microtubule breakdown or potassium deprivation. Mol Med 5, 477-489. http://dx.doi. org/0158

Waldmann, T., Rempel, E., Balmer, N. V. et al. (2014). Design principles of concentration-dependent transcriptome deviations in drug-exposed differentiating stem cells. Chem Res Toxicol 27, 408-420. http://dx.doi.org/10.1021/tx400402j

Wenzel, C., Riefke, B., Grundemann, S. et al. (2014). 3D highcontent screening for the identification of compounds that target cells in dormant tumor spheroid regions. Exp Cell Res 
323, 131-143. http://dx.doi.org/10.1016/j.yexcr.2014.01.017

Wind, M. and Stokes, W. S. (2010). Developing performance standards to expedite validation of innovative and improved test methods. ALTEX 27, 97-102.

Wink, S., Hiemstra, S., Huppelschoten, S. et al. (2014). Quantitative high content imaging of cellular adaptive stress response pathways in toxicity for chemical safety assessment. Chem Res Toxicol 27, 338-355. http://dx.doi.org/10.1021/ tx4004038

Yoon, M., Campbell, J. L., Andersen, M. E. et al. (2012). Quantitative in vitro to in vivo extrapolation of cell-based toxicity assay results. Crit Rev Toxicol 42, 633-652. http://dx.doi.org/ 10.3109/10408444.2012.692115

Young, D. W., Bender, A., Hoyt, J. et al. (2008). Integrating high-content screening and ligand-target prediction to identify mechanism of action. Nat Chem Biol 4, 59-68. http:// dx.doi.org/nchembio.2007.53

Yum, K., Hong, S. G., Healy, K. E. et al. (2014). Physiologically relevant organs on chips. Biotechnol J 9, 16-27. http://dx.doi. org/10.1002/biot.201300187

Zanella, F., Lorens, J. B. and Link, W. (2010). High content screening: seeing is believing. Trends Biotechnol 28, 237-
245. http://dx.doi.org/10.1016/j.tibtech.2010.02.005

Zang, Q., Rotroff, D. M. and Judson, R. S. (2013). Binary classification of a large collection of environmental chemicals from estrogen receptor assays by quantitative structure-activity relationship and machine learning methods. J Chem Inf Model 53, 3244-3261 . http://dx.doi.org/10.1021/ci400527b

Zock, J. M. (2009). Applications of high content screening in life science research. Comb Chem High Throughput Screen $12,870-876$.

\section{Correspondence to}

Marcel Leist, PhD

Doerenkamp-Zbinden Chair for alternative in vitro methods

University of Konstanz

Box M657

78457 Konstanz

Germany

Phone: +49 7531885037

Fax: +497531885039

e-mail: marcel.leist@uni-konstanz.de 